\title{
On the Improvement and Deepening of the Chinese Manufacturing Informationization Construction
}

\author{
Zhang Huiwen, Huang Hai \\ Business Administration Department, Shanghai Finance University, 995 Shangchuan Road, Pu \\ Dong New Area, Shanghai, China \\ Room 1101, No.3, Lane 850, Si Ping Road, Shanghai, China \\ Zhw502@yahoo.com.cn, huangp66@sina.com
}

Keywords: manufacturing, informationization, improvements

\begin{abstract}
This paper discourses on the status of China's manufacturing industry informationization construction work, the main problem it is currently facing, and how to resolve these issues to improve and deepen the manufacturing enterprise informationization construction level, to help enterprises to avoid detours in the course of informationization, and make information technology to really serve manufacturing enterprises, and become the source of the power of enterprise development.
\end{abstract}

\section{Introduction}

"Made in China" has entered the third development decade in 2011. China being in the late process of industrialization, more than 200 kinds of Chinese industrial products' output ranks first in the world, the size of the manufactured goods also ranks first in the world, China has become a veritable "World Manufacturing factory." However, that Chinese manufacturing is big but not strong, and is still in the middle and lower reaches of the global industrial chain, is also an indisputable fact. In the development process in the next decade, facing the implementation of the "re-industrialization" strategy of developed countries in the era of post-financial-crisis, and the new situation that green manufacturing emphasizes on the recycling economy and social responsibility, especially the formation of the competitive global marketplace, companies face increasingly blurred market boundaries. And the situation is bound to promote the new round of reshuffle in the global manufacturing industry. China's manufacturing industry will be inevitably pushed into the restructuring and upgrading process of "from the world processing centre to the world creating center". Informationization of manufacturing industries is the inevitable choice of the development of manufacturing development, and development of information technology has provided technical support for this trend. In order to move towards the manufacturing power, China as a manufacturing country has to adopt single option of informationization.

However, although there is some success in the development of informationization of China's manufacturing industry in the previous two decades, the comprehensive level remains a cause of concern. Its breadth and depth is still lagging behind finance, telecommunications, and large-scale public service industries, which does not match the global position of "Made in China". For this reason, driving the profound integration of informationization and industrialization to drive industrialization through informationization, exerting advantage of backwardness, achieving development of productivity by leaps and bounds, promoting the upgrading of manufacturing industries, and accelerating the transformation of the mode of economic development, should be the strategic focus of the improvement and deepening of the Chinese manufacturing informationization construction. 


\section{A The main problem facing the informationization construction of China's manufacturing industry}

(A) Macro-level issues

a. The uneven development of the construction of informationization, and the low overall level of information construction

The informationization of Chinese manufacturing has shown strong regional, industrial and scalar characteristics, and the development is very uneven. Geographic concentration of manufacturing is obvious. Through the application of information technology, some industry groups reflect the cluster size advantage, the southeast coastal area's manufacturing enterprises are particularly so; whereas, the backward northwest area's manufacturing companies' failure of understanding IT or lack of talent and funds has resulted in the great gap between the east and the west in the popularization and application of information technology.

Moreover, the levels of promoting, applying and sharing IT are uneven in the manufacturing enterprises, the petrochemical, automotive, and steel industries have a high informationization level, which approximates the international counterparts, while the textile, light industries, have lower level of informationization construction as a whole. In addition, the informationization construction of enterprises of different sizes is not balanced, in that state-owned large and medium-sized manufacturing enterprises have a higher level of informationization construction, while the small enterprises have a lower level of informationization construction. The imbalance of the construction and development of informationization of manufacturing industries has ultimately led to the uneven development of the levels of industrialization of the Chinese manufacturing industries.

b. Low informationization construction investment proportion and the lack of compound informationization human resources

According to data released by the National Bureau of Statistics, China's industrial-based secondary industry GDP in 2010 reached 18.6 trillion yuan, an increase of 18.3 percent. However, China's manufacturing industry informationization investment in 2010 was only 52.92 billion yuan, growth rate of $15 \%$, which indicates that China's manufacturing industry informationization investment accounted for less than $0.3 \%$. Financing channels for most enterprises are still few, and external funding sources are in short supply, so it is difficult to provide follow-up funding for the later development of the manufacturing enterprise informationization, leading to incomplete informationization. Manufacturing enterprises' lack of information technology personnel, especially high-level compound talent is still a major factor restricting the development of enterprise informationization. Manufacturing informationization involves multidisciplinary integration, and implementation of informationization not only needs computer technical personnel, but also needs managerial talents, particularly compound personnel who not only understand techniques and processes, but also the complex computer technology and management. The survey showed that 80.6 percent of manufacturing enterprises lacked information technology staff, even if national key manufacturing enterprises have a talent gap of 62.3 percent.

c. The information technology market is not perfect, the construction of enterprise informationization lacks necessary planning

The hardware and software products lack standardized management and guidance, and show a characteristic of "small, many, scattered", the market is characterized by disorderly competition and vicious competition. It is difficult to ensure that informationization projects meet the requirements of the manufacturing enterprise, which is not conducive to the informationization construction of China's manufacturing enterprises. Manufacturing software products, for example, often have a shortcoming that software R \& D institutions are small and can only deal with small projects; software products are many, but universal, intelligent and high-end products are in short supply, compatible, integrated, and adaptable products are in short supply, which results in a large number of "islands of information", which block information to each other. Their information resources can not be shared, which greatly affects the efficiency, effectiveness and competitiveness of the manufacturing sector, and hinders the process of informationization. 
d. The "coding system" of Information standardization has not been established, and the effectiveness of construction is difficult to unified

Manufacturing informationization has not yet established international standards, national standards, industry standards, professional standards, system standards, and certification standards, which results in the disunity of manufacturing informationization of the state, which is characterized by various enterprises pulling their own sets and running their own roads. The core of standardization is to establish a "coding system" in conformance to international standards, there is no real informationization without standardized "coding system". Coding system is the basis of informationization, sharing of resources, office automation, automatic statistics, production automation, and software compatibility and sharing. Coding system is a bridge connecting "islands of information", the key to the success of informationization, a fast, accurate and effective means of retrieving information, and the most difficult point to advance informationization.

(B) The meso level

a. The issue of industrialization and industrial synergy is outstanding, and the integrated effect of informationization is difficult to take effect

In terms of the scale or nature of the industry, Chinese manufacturing companies vary widely, so different enterprises have different application requirements. As the Chinese saying goes, "There is a huge barrier between different industries", so an ERP system set to support the industry characteristics and able to be customized with differentiation is particularly important; at the same time, the competition within the manufacturing sector has been no more that between enterprises than that between industrial clusters, and industrial chains. Whether the new ERP systems can use the latest technology, especially the new technologies and new ideas derived from cyberization, and form perfect link between industrial synergistic requirements, is also an outstanding issue during the process of informationization process of local manufacturing industry.

b. Local administrative departments in charge of manufacturing lack motivation, enthusiasm and initiatives to promote informationization

Facing the long-term and complex nature of informationization work, various local technological authorities or economic authorities obviously have insufficient drive, and can not closely integrate the manufacturing informationization work to the pillar industries of local economic development, or provide information technology services and support to the development of its pillar industries. Informationization projects are not strong, in that they lack continuous investment in human, financial and material resources, and can not give full play to the enthusiasm and initiative of its work.

c. Service application platform system is imperfect, and can not form a rapid response

In the operation chain of manufacturing industries, in view of any role and object in the industrial chain, service is a particularly important part. An application platform to quickly respond to market demand is needed in various levels such as production, testing, promotion, use, trading, clearing, maintenance, logistics. At present, the vast majority of domestic enterprises have many shortcomings in this regard. Due to the constraints of the service platform system, companies can not develop quickly, while on the other hand, those companies who value service are often able to come to the forefront of the industry, the forefront of the world.

(C) micro-level issues

a. Construction of informationization infrastructure remains weak

Currently many manufacturers put more emphasis on the maintenance issues such as "operations support" and "corporate security", while the situation of the hardware equipment, such as the computer room, the number of its own server, the computer ownership rate, and interconnection rates, is not ideal, there are still outstanding phenomenon like that the number of hardware facilities is inadequate and aging.

b. The control mode of Implementation of informationization still lags behind

Constrained by traditional concepts, many enterprises continue to adopt the way of sets of plans, which has high reserves of inventory and work-in-process, and entails big working capital; artificial cost accounting generally only calculates the product cost, and cost data acquisition being 
artificially imputed makes cost calculation inaccurate, so generally the calculation of standard cost is usually not carried out, and cost analysis is rarely carried out, neither. So production planning model is backward, and cost control is poor.

c. Apparent lack of informationization quality and commitment

Comprehensively analyzed from the informationization aspects of annual budget, annual budget growth, leadership support, policy support and a sense of identity, most of the manufacturing enterprises are mediocre. As to the quality of the informationization, the degree of integration between IT and enterprise business is generally low. All those will affect the benefits information brings to the enterprise, and thus directly or indirectly affect corporate capital investment and management support in informationization.

d. Informationization innovation and management capacity is still low

In terms of the application of informationization software technology, manufacturing enterprises are still at a low level, whose innovative mechanisms are not worth mentioning. As regards management decision-making, decision-making of the "number one" is still an outstanding problem. This bureaucratic decision-making model not only reduces the professional level of the informationization program, and the one-sidedness of the individual decisions leads to more mistakes, thereby reducing the probability of informationization to bring high returns, and ultimately affect the confidence in the information input, hence a vicious circle.

\section{B Measures to improve and deepen informationization construction of manufacturing industries}

(A) The government should adhere to the guidance, macro-planning and regulation of the direction of development of the Chinese manufacturing informationization

a. To lead the planning, clear positioning, targeted construction of information

First of all, an overall planning should be done to the informationization construction, it should be clarified that the positioning and major work of manufacturing industry informationization is service, that is, information content services, technical means services, trading platform services and organizational decision-making services for businesses, industries, sectors and local development. We should give full consideration to the enterprise development, starting from the most prominent bottlenecks, and gradually seek practical results within our capabilities. Secondly, we must strengthen the policy guidance and control for informationization construction, and promote informationization of manufacturing industries by means of policy formulation, establishment of standards and information infrastructure, etc. Finally, we should use geographical advantages and functional differences in the industry to carry out the horizontal and vertical division of labor and integration, prompting industries and enterprises to define their respective positioning, develop their own core competitiveness, aim at their own informationization construction to from a fundamental solution to the problem of uneven development between regions, industries and even enterprises during the process of informationization construction.

b. To increase investment, accumulate talent, and continue to strengthen the strategic guarantee of the informationization construction

Informationization is a systematic engineering characterized by high technology, high standards, high intelligence and high input. The strategic guarantees of the implementation of manufacturing Informationization are personnel and funds. Manufacturing informationization construction work requires a wide range of technical and management personnel, in particular compound personnel who not only understands technology but also understands management. So the state should from a strategic height adopt a long-term informationization talent strategy, and actively create a favorable policy environment to introduce and absorb businesses informationization personnel. It is necessary to carry out specialized complementary training, and also train personnel from the tertiary education system, and constantly improve the manufacturing informationization technology training and consulting service system. Further capital investment can be done through the reorganization of assets, public financing, domestic and foreign investment and capital operation mode. 
Multi-channels and multi-forms of financing can be used to increase the capital input in the informationization construction to provide funding for the implementation of informationization of the manufacturing industries.

c. To establish standardized informationization "coding system", and constantly reinforce the strategic basis of the informationization construction

To establish standardized, and scientific coding system is the strategic foundation of the manufacturing informationization. The practice has proved, standardized coding system will transform the "islands of information" that the manufacturing sector has formed into "information fields", or "Information Oasis". To promote information technology, the state should first of all pay attention to standardized coding, and coding should be put to a strategic height, as to be treated equally to software. The state should strengthen the research and input of material resources, capital investment of coding theories, techniques and methods such as national informationization standards, classified theme coding, subject classification coding, special coding, universal coding, international standard coding. The national standardization bodies, National Numbering Agencies, and national informationization agencies should work together to make "strategic foundation" a reliable basis to promote informationization construction of manufacturing industries.

(B) To strengthen collaboration, to create a platform, and delegate authority to mobilize the enthusiasm of the local government to promote informationization construction

a. To form synergistic integration effects, and strengthen the supply chain competitive advantage through IT

On the basis of the complete informationization construction within manufacturing enterprises, upstream and downstream integration synergies and integration effect should be formed. Firstly, informationization work of manufacturing industries should be organically co-ordinated and integrated with social sustainable development and industrial structure adjustment; Secondly, it should be closely integrated with the pillar industries and key tasks in enterprises to promote synergistic development of common hardware and software techniques and products of informationization of manufacturing industries by means of supporting industrial technology alliance; finally, by supporting the upstream and downstream data-link software vendors' conglomerate to be transformed into the information service provider, form the upstream supplier management and inquiry system, and the downstream customer relationship management and sales process management system in order to build the perfect ERP.

b. To strengthen the development and construction of the service application platform system, and form the ability of enterprises to respond quickly

The starting point and destination of the informationization construction is to use advanced information technology to have access to all kinds of information needed by the enterprise quickly and accurately. To strengthen the construction of services application platform system of informationization of the manufacturing industries, it should provide better services to support the development of the manufacturing industry, provide a full range of services in manufacturing companies. In this process, we should primarily address three issues:

(a) exploring the road of manufacturing services development, the development of digital platforms and systems for product life cycle, supporting manufacturing enterprises to occupy the high-end links to serve as the core of the industry value chain;

(b) exploring the public service platform to support the manufacturing sector, supporting manufacturing outsourcing and common technology resources services, promoting the development of the third-party service;

(c) exploring the mode of development that informationaliztion supports the penetration and integration of manufacturing and service, and promoting the value chain of the modern manufacturing industry and the formation of the modern manufacturing industrial system.

c. To vigorously mobilize the enthusiasm of the local government to construct informationization of manufacturing industries, highlighting the characteristics and effectiveness of informationization construction. 
Further delegation of autonomy of informationization work of manufacturing industries into the hands of local government should be an important development trend of China's manufacturing industry informationization projects, which is also bound to further mobilize the enthusiasm of the local government sector, to promote the manufacturing industries' informationization engineering to be closely integrated to distinctive local economic and industrial development, hence further prominence of the characteristics and effectiveness of the promotion of manufacturing industries' informationization engineering. In this process, we should strengthen the construction of manufacturing informationization support and service organizations of the provinces and cities, and inculcate into the provinces and cities commitment to the promotion of manufacturing informationization engineering. Provinces and cities with similar economic and industrial development can also take the mode of joint promotion and joint commitment to the national manufacturing informationization engineering projects.

(C) To pragmatically locate the introductory point, and constantly deepen the construction process of informationization of manufacturing enterprises

a. To be set for Informationization construction to establish a good foundation for informationization

First of all, an overall planning should be done to the informationization construction. We should give full consideration to the enterprise development, starting from the most prominent bottlenecks, and gradually seek practical results within our capabilities. Secondly, we must strengthen the leadership of the organization of informationization construction. The establishment of informationization technology must not only have technical basis, but also management infrastructure. Enterprises should solve their own problems, advance informationization on the basis of rectifying and strengthening management, and use informationalization to promote recycling and innovation of business management. We should continuously improve the managerial system, establish stable and reasonable regulatory agencies and business processes.

b. To establish a sound production planning and control system, and strengthen financial management and improve their cost accounting

For different types of production, we should use advanced production planning and control methods. We should focus on the entire supply chain to break the traditional manual production plan to control the kind of scattered, discontinuous, static, and inaccurate planning mode, establish sales, production, procurement, continuous, dynamic, accurate production planning and control mode. We should formulate material requirements planning, maximally shorten the production cycle and the procurement cycle, and respond quickly to customer demand, maximally shorten the production cycle and the procurement lead time, reduce inventory of funds used to quickly respond to customer needs. We should use advanced cost accounting methods to provide a reliable basis for sales quotes, financial accounting and cost analysis, break the problem of reducing costs.

c. To increase innovation, improve manufacturing enterprises' information management level

Manufacturing enterprises are the subjects of innovation of informationization, so they should increase efforts for technological innovation, establish sound corporate high-tech research and development centers, speed up high-tech and advanced applicable technologies to accelerate the upgrading of traditional products; stringently demonstrate the feasibility of applied information techniques for enterprise development; use the allotment of shares or bonuses to increase the enthusiasm and initiative of innovation and application of IT for enterprise staff; relies on institutions of higher learning for information technical training for managers and technical personnel of small and medium enterprises; appropriately increase information technology investment, actively expand financing channels; build a democratic and scientific information management and innovative mechanisms, in which management personnel and technical staff at all levels of various departments, as well as third-party advisory body take part in decision-making. 


\section{References}

[1] Porat M. V. The Information Economy: Definition and Measurement [J]. Washington, DC. Office ofTelecommunications, US department ofcommerce, special publication, 1977.

[2] Li Jingwen, Zhengyou Jing, [Japanese] Komatsu Kawasaki Qingjie.Piper G information technology and economic development [M].Beijing: Social Sciences Documentation Publishing House, 1994.

[3] Liu Youhua, Qi Aihua, Du Jia. Academic site evaluation index system and application [J].Information Science, 2008, 26 (01): 64 - 68.

[4] Chen Chuan Hung.High-tech enterprises' technological innovation ability evaluation system [J].Coal Economic Research, 2008 (8) :43-46.

[5] Xueyong.Innovation [M].Beijing: People's Publishing House, 1 July 2011. 